THE

i) OURNAL

Baldanza, J. (2019). The iJournal 5, 1,

1-13. 10.33137/ijournal.v5i1.33462

\title{
Health Theatre: Recognizing and subverting the tactical farce of the medicalization of everyday life
}

Jessica Baldanza

\section{Abstract}

This article considers the implications of Western health and wellness culture's strategic co-option by industry, embodied by the rise of wearable tech, the commodification of the self-help movement, and the datafication of the human body. Said culture has come to bear the paranoia observable in the West's approach to national security, which is widely dubbed as "security theatre". "Health theatre" is put forth here as an analogous phenomenon to security theatre, wherein the populous is subject to invasive scrutiny by governing structures, enacted in the name of their own wellbeing. Both phenomena are characterized by their sensationalist rhetoric and effective impotence in producing results consistent with their alleged purpose. Health theatre can best be understood as an organic symptom of the broad medicalization that has permeated Western culture over the past century. Medicalization pathologizes the scope of human experiences, while situating the problem at the level of the individual where solutions are then couched. Further, by positing health as an elusive state to be perennially pursued, the individual is left in a perpetual state of dependency. Should health theatre proliferate, the West will continue to suffer a fear-based, atomizing system of health promotion. Means of resistance to health theatre are proposed here as a return to engagement with communal forms of reproductive care that reject pathologizing diversity in psychological and somatic states.

Keywords: Medicalization, optimization, surveillance, bio-power, security theatre 


\section{Introduction}

Medicalization, according to the $20^{\text {th }}$ century sociologist Irving Zola, is a twin phenomenon: it expands "professional power over wider spheres of life" and extends "the range of social phenomenon medicated by the concepts of health and illness." (Crawford, 1980, p. 369). The former facilitates the latter, and vice versa. To remind oneself about the origin of the phrase is to acknowledge that the broad pathologizing of human experiences is a relatively recent process, and that the narrowly defined state of normalcy in contemporary Western health and wellness culture is a moralized construct.

A prescient example of the positing of health as a precarious state indicative of virtue is the pairing of perpetual-use wearable sensor technology with the growing atomization and privatization of care that cultural anthropologist Natasha Dow Schüll calls "Data for Life." Wearable technology that collects, records, and analyzes bodily processes (ex. heart rate) and lifestyle habits (ex. sleep cycle), leverages the consumer's desire to quantify a state of wellbeing into something objective, and configures the human as a user, wherein "flesh" is reduced to "pure information" (Browne, 2016, p. 26). In addition to changing the way we relate to our bodies, wearable tech has unsettled the heretofore dichotomous relationship between wellness and illness. Unprecedented access to our invisible biology by way of wearable technologies like Fitbit or Garmin instigate an anxious state of vigilance, borne of a sense of obligation to selfmanage our health amidst the moralization of this new health consciousness. Ethical questions surrounding the nudging of user behaviour aside, the creators of wearable tech products are known to habitually collate mass user data and share it with other companies and governing bodies (Till, 2014, p. 447). The introduction of third parties into the intimate conversation between an individual and their Fitbit make for what Browne calls "participatory monitoring" (Browne, 2015, p. 15), in which users obliquely opt-in for reflexive, external observation and judgement. This moralized health and wellness culture that “... situates the problem of health and disease at the level of the individual" (Crawford, 1980, p. 365) inspires a willful surrender of one's own borders to external authorities, giving rise to "health theatre," which adopts a congruent framework of control to that of "security theatre."

The true significance of said technology is found at this intersection of health and surveillance, or more precisely, the body and surveillance. The aggregate nature of data collection by way of wearable tech is where we find an example of Foucault's "bio-politics of the population" (Cisney \& Morar, 2015, p. 5), wherein the disciplinary mechanisms enacted on the micro-level coalesce to make up the statistical grounding that legitimates the implementation of governing policy and control. Outside of explicitly medical contexts, bio-power's influence in 
the coordinated control of the populous is nowhere more evident than within the militarized site of the post-9/11 airport, where layers of orchestrated implicit and explicit surveillance engender submission in even the boldest traveler.

Despite all the bureaucracy, the US Transportation Security Administration (TSA) has been found to be ineffective in their practical work as intermediary, exposed as characters in what cryptographer and self-proclaimed public-interest technologist Bruce Schneier coined as "security theatre." In his 2003 book Beyond Fear: Thinking Sensibly About Security in an Uncertain World, Schneier defines security theatre as "the practice of investing in countermeasures intended to provide the feeling of improved security while doing little or nothing to achieve it" (Schneier, 2003, p. 38). Likewise, the broad pathologizing of human experiences defined by the medicalization of everyday life, and embodied within the wearable tech industry, is proven to have little to no material effect other than to engender artificial needs of the populous for which they rely on external authority figures to legitimate and manage.

The investigation articulated in this essay begins with defining and contextualizing "the medicalization of everyday life" and then identifying the methods by which medical industries generate dependency in the populous. This is followed by a case study which elucidates capitalism's comprehensive hijacking of the resistant practice of self-care. It is at this point that the heretofore proposed concept of health theatre is substantiated by comparisons to the developmental trajectory of security theatre, while alluding to the dangers of the datafication of citizenry. The research concludes with a synthesis of these ideas, and proposes a two-pronged course of action to be taken as a means of active resistance to health theatre and widespread medicalization.

\section{The Medicalization of Everyday Life}

In order to understand how the citizenry comes to subject itself to surveillance technologies and a state of hypervigilance, it is essential to define and contextualize "the medicalization of everyday life" (Crawford, 1980, p. 365) as the expansion of the jurisdiction of medicalization over the past two hundred years.

In order to comprehend the contemporary Western approach to health systems, one must consider the progressive abandonment of the afterlife concept over the course of two centuries, wherein traction gained in the human sciences corresponded to a recession in the power of organized religion (Illich, 1975, p. 109). Theologian Ivan Illich situates the genesis of our Western conception of disease and health amongst the scientific advancements of the $17^{\text {th }}$ century, where, for the first time, physicians would replace clergymen, and sickness would be 
regarded as "a public affair" rather than solely the concern of the afflicted (Illich, 1975, p. 109). This was not, according to Foucauldian theory, an empathetic means by which to share the burden of mortality, but rather to implement a new form of power: "bio-power," the modern incarnation of power relations constituted by the concurrent enactment of "disciplinary power mechanisms of the body and the regulatory mechanisms of the population" (Cisney \& Morar, 2015 , p. 5). Bio-power initially operated on the micro level, where the human body was regarded in terms of "inputs and outputs," a machine to be directed by disciplinary mechanisms and institutions as a means to extort its manpower (Cisney \& Morar, 2015, p. 4). Disciplinary measures would not take the form of explicit regulation, but instead characterize the conduct of normal behaviour, compelling the machine-body to engage in self-governance.

This social engineering of health in the name of "progress" (i.e. optimization of the individual in order to engender peak productive functioning) would inspire the revitalization of the hospital institution, which up until then had been the final stop for the physically, mentally, and otherwise ill. It was not until the Congress of Vienna (1814) that hospitals and medical schools became widespread and instrumental (Illich, 1975, p. 111). By the late $19^{\text {th }}$ century, the doctor had emerged as saviour ${ }^{1}$, and ailments were recognized as objective diseases. Over a period of roughly two hundred years, universal standards in nearly every strata of society would be implemented to accommodate administrative management (Illich, 1975, p. 26). By the middle of the $20^{\text {th }}$ century, the hospital became a "compartmentalized repair shop" (Illich, 1975, p. 114), rendering the human body a piece of technology, deemed fit only when adhering to standards of normalcy sanctioned by governing bodies. It was around this time that Crawford's notion of the broad medicalization of everyday life, that so thoroughly characterizes the present, was institutionally, culturally and individually embraced.

From this point forward, we observe an ever-diminishing distinction between what cultural critic Susan Sontag (2001) refers to as the "kingdoms" of the well and of the sick (p. 3). A citizenry formally regarded as healthy would now be subject to the neurotic vigilance of increasing biological data, creating a dependency on a medical system and their technological trappings which produce little to nothing in material results, but facilitate an illusion of proactive care, of health theatre.

\section{Diagnosis Dependency}

Symptomatic of this extension of the medicalized into new terrain is the essentialization of health and illness in discourse. Health is now defined by adherence to situated standards

1 Not, Illich notes, as a result of their efficacy, but as opportunists filling a vacuum created by the failure of political 
of normalcy, and illness is now applied to behaviour marked deviant (Crawford, 1980, p. 369). Here, illness is imbued with a moral authority granting legitimacy to deputized health professionals to perpetuate salutary incarceration. Likewise, the medical structuring of illness as a kind of deviance serves to "reproduce patriarchal structures and values" (Crawford, 1980, p. 378). Classification of said deviance/disease is defined by the social organization of the society in which one exists. In accordance with the societal tendency to respond to the unknown with fear and blame, the more obscure the underlying cause of the disease, the more it "...tends to be awash in significance" (Sontag, 2001, p. 58). For instance, the long history of pathologizing same-sex attraction occurs in societies structured around the cisgender heterosexual union. The initial AIDS crisis targeted the already pathologized demographic of homosexual men, who were in turn deemed culpable for the deadly affliction as a result of their sexuality (Sontag, 2001, p. 114).

Crucially, as illness has gradually come to be something identified from within, so too has the "cure". Advancements in treatments for infectious diseases reinforced the notion that health was a matter of etiology, and thus any attempts to consider social or political factors in the development of illness were denied (Crawford, 1980, p. 372). Chronic and degenerative diseases, for which there are no cures and sparse relief, are met with the endorsement of individual strategies for prevention (Schüll, 2016, p. 2). The certainty with which this rationale is applied renders political ideology as objectivity, reinforcing the undue authority of the physician, while, as per neoliberal dogma, the blame and responsibility lie with the individual as opposed to the social order (Crawford, 1980, p. 373).

The peculiar dichotomization of health and illness, with a preference for illness, is not an accident, but the manner by which medical professionals maintain power as patients are made dependent on their judgement (Crawford, 1980, p. 373). This is consistent with the diagnostic predisposition towards locating illness in any conceivable quality that exists outside the established normate, which, combined with inevitable diagnostic error, makes for a fearful population, beholden to medical authority. Once diagnosed ill, a patient is isolated, unlikely to retaliate against the bureaucratic and corporate growth they now believe to be dependent on for survival. This logic has been compounded by the constant, minute diagnoses we receive from the authorized agents of our wearable tech (ex. Fitbit, Garmin), so that the once considered neutral state of "healthy" (more or less meaning displaying no observable symptoms) is merely asymptomatic, or pre-symptomatic (Schull, 2016, p. 3). The perpetually sick, or pre-sick individual is rendered a permanent dependent, compliant lest they teeter into the realm dubbed "ill." The state of deviance (i.e. "sick") becomes so familiar as to render neutral well-being strange and unsettling, or in other words, "total well-being engenders total dis-ease" (Crawford, 1980, p. 382). The individual becomes mistrustful of their lack of perceptible symptoms and pursues 
diagnosis where there is no cause, subjugating themselves to institutionally sanctioned lifestyle ideology.

\section{Co-opting Resistence: The Case of Self-Care}

In his 1980 essay Healthism and the Medicalization of Everyday life, Robert Crawford proposes "self-care" and "self-help" practices as means of communal resistance to oppressive clinical infrastructure (Crawford, 1980, p. 366-67). This notion was expanded upon and popularized by feminist Audre Lorde, who encouraged practices of reproductive $\operatorname{care}^{2}$ in the commons as a means of fortification for the "battle" against raced, classed, and gendered societal structures (Sharma, 2017, p. 14). In the nearly four decades since Crawford and Lorde's respective advocation of self-care, the movement has succumbed to the most vicious and nullifying kind of "capitalist realism." Capitalist realism is a term coined by writer, critic, and cultural theorist Mark Fisher to describe "the widespread sense that not only is capitalism the only viable political and economic system, but also that it is now impossible even to imagine a coherent alternative to it" (Fisher, 2009, p. 2). Self-care (which Crawford uses interchangeably with self-help), was hijacked by opportunists after Hillary Clinton's loss in the 2016 American federal election. According to Google Analytics, web searches (a potential harbinger for a contemporary commercial phenomenon) for the term saw a substantial spike one week after Donald Trump's win. The concept gained traction overwhelmingly amongst affluent, straight white women (Kisner, 2017). Galvanized by the exponential nature of the social internet, the association of the neoliberal political figurehead guaranteed the distortion of the formerly political movement.

This particular strain of self-care, which media studies scholar Sarah Sharma refers to as "selfie-care," is historically unique in its embrace of individualism, ardent consumerism, perpetuation of normate ${ }^{3}$, seemingly self-evident female embodiment, and synthetic radicalpolitical affiliation: the political language of "selfie-care" is composed of "plastic words" that obfuscate its essentially hollow, commodifying nature. Selfie-care relies on the objectification of the populous into individual users, as "one cannot function as a user without conforming to the modes of use that have been designed into a system" (Lacey, Caudwell, \& Beattie, 2019). The kind of tech-humanism undergirding selfie-care only appears radical due to its embracing of technology, but actually relies on an archaic, Enlightenment-era notion of the "human" which assumes able-bodied, white, heterosexual and cisgender identity, severely limiting the possibility 2 Sharma identifies reproductive care as a kind of communal labour engaged in so that "others can eat, sleep, and rest." (Sharma, 2017, p. 14)

3 “...the generalizable human being or the body-type thought to be normal” (Hall, 2015, p. 5).

4 [defined by linguist Uwe Poerksen as] “...word husks that one can wave around, making oneself important, but which can say or do nothing" (Illich, 1990, p. 27). 
of radical disruption of the governing bodies' ideologies which seek to perpetuate the normate.

The self-care cum selfie-care phenomenon embodies health theatre in its promotion of the normate, which serves to pathologize the inevitable variability in the human experience. This generates a sense of fear which atomizes the populous into individual actors pursuing an elusive state of health through commercial means. Dependency, far from being eliminated, is transferred from societal institutions to private and unregulated designers, manufacturers, and distributors of products. In this case study, reparative communal movement made in goodfaith is co-opted by private interests to perpetuate the status quo by way of the estrangement of individuals from one another. The ends of such an endeavour by disciplining institutions are in accordance with those of bio-power's second pole, wherein a docile, distracted, consuming citizenship serves the neoliberal agenda by way of popular deference.

\section{Security Theatre, Health Theatre}

In her 2015 book Dark Matters: on the Surveillance of Blackness, Simone Browne notes that the September $11^{\text {th }}$ terrorist attacks are consistently misdescribed as lacking historical precedent. Browne (2015) goes on to identify several instances of the hijacking and weaponization of a commercial aircraft in the U.S. and abroad before 2001 (p. 28). The significance of this mischaracterization of circumstance is in the way it serves security theatre. Theatre is nothing without drama, and the more unprecedented the attack is portrayed, the more reasonable extravagant measures of response are considered to be. Following 9/11, passengers across the globe would see a transformation in the culture, organization, and experience of flying as airports were militarized and benign travellers implicated.

Lacking a defining event comparable to $9 / 11$, the transformation in health culture throughout history initially occurred slowly, and then exponentially following first the Scientific Revolution, and then accelerating globally following the rapid privatization of public life and industry (including public health services) of the Reagan-Thatcher era (Murray \& Ouellette, 2008, p. 231-233). Certainly, the history of health in the Western world is not without its galvanizing crises (lest we forget mad cow disease, Ebola, swine flu, the West Nile virus, etc.), but it is the less well-defined, more degenerative diseases that have most served the private interests of those who benefit from widespread healthism (a way of viewing a problem through medicalization). Diseases like depression and cancer have come to be the pet causes of the health and wellness industry for their apparent origins in individual behaviour which appeals to the neoliberal ethos of personal responsibility.

The gradual nature and obscure origins of such diseases inspire a constant state of dread and fear akin to the national security fear present in post-9/11 airports. As Schneier highlights, 
the statistical chance of being killed by a terrorist is inconsequential (Schneier, 2007). The superabundance of sensationalist media coverage on the matter lends credence to the hysteria through tactical fear mongering, engendering public dependency on their services for insight. Likewise, the growing number of human experiences and behaviours that have been classified as syndromes, disorders, and diseases by legitimizing medical terminology serves to make a constant state of health-related anxiety appear rational.

In this light, the vast allowances we grant our medical authorities seems justified, and the willful adoption of surveilling devices of wearable tech, or invasive and potentially harmful diagnostic procedures, seems a small price to pay for our wellbeing. And yet, in spite of all the expensive and drastic measures, neither security theatre nor health theatre are materially effective in achieving the championing of individual and national sovereignty they claim to be in service of (Young, 2018). Bottles of liquid, sharp objects, and harmful devices consistently make it past the TSA (Levenson, 2014), just as the development of lifestyle diseases (ex. obesity) continue unabatedly amidst the proliferation of wearable tech. The failures of both the TSA and the wearable tech industries can be found in, among other things, their reliance on total user compliance. Discrepancies in the results of wearable-tech may be explained by studies observing that "mainstream consumers do not use wearables consistently or as intended" (Schull, 2017, p. 4), rendering the faith healthcare policymakers and insurance companies have in wearable tech to "mitigate lifestyle diseases" and "help solve the problem of medication compliance" somewhat naïve (Schull, 2017, p. 4).

When confronted with the bleak results of their extensive measures, arbiters of national security claim that the actual results are beside the point of the TSA, that security theatre exists wholly in service of the illusion of safety to assuage fear (Levenson, 2014). This justification conveniently elides the matter that a fearful populous is a more pliant one, and that the presence of the TSA serves to incite fear as readily as it may allay it. Ordinary citizens are obligated to endure undue scrutiny at best, and wrongful persecution at worst. Likewise, a culture of vigilant monitoring in healthcare subjects healthy people to a state of dread, invasive diagnostic procedures, the opportunity for misdiagnosis and unnecessary treatment. For instance, most prostate cancers grow so slowly that one could go their entire lives without becoming symptomatic, yet the word cancer elicits such hysteria in patients that "9 out of 10" (Ropeik, 2011) undergo highly invasive and life-altering treatments. Placebos such as the dramatic measures enacted by the TSA, the bio-monitoring of one's health by means of wearable tech, or the pre-emptive screenings by medical authorities, might be worthy pursuits were they not to come at such a high expense. 


\section{The Inferiority of Global Systems}

The datafication of health creates a constant dependence on authority figures and technological infrastructure, generating the constant illusion of need, and the subsequent consumption of services and products in a preventative effort (Schwartz Cowan, 1983, p. 7). In these circumstances, the user knowingly or unknowingly is a colluding participant in their own surveillance and commodification, engaging in the "participatory monitoring" (Browne, 2016, p. 15) of their biological processes and lifestyle habits. This aggregated data is essential for Foucault's second pole of bio-power, the regulatory mechanisms imposed at the scale of the population. The constant stream of data aggregated from their wearable tech is collected and analyzed not only for the user's benefit but for the benefit of the tech's producers and whomever they choose to share it with (Schüll, 2016, p. 2). As we are already seeing instances of the convergence of personal tracking and employer monitoring (Schull, 2016, p. 45), it is safe to assume citizen monitoring of self-tracking data is next, if not already occurring.

While everyone under these new regimes of health and security experience scrutiny at one point or another, certain individuals and demographics are labeled as more suspicious than others as per "panoptic sorting" 5 by governing bodies. Who is classified as more or less suspicious depends on their perceived transparency, a factor that is determined not by an individual's willingness to cooperate with governing authorities, but with their ability to embody the normate. Inevitably, racialized, classed, gendered, and differently abled persons and groups are deemed dangerously "opaque" (Hall, 2015, p. 1), and thus threatening within the security infrastructure implemented in the name of maintaining a vague notion of safety. Like the health-deviant shamed for their disease or benign lifestyle choices, the opaque body is told that exceedingly invasive measures of surveillance are not only justified, but that this invasion was brought unto themselves through their refusal to cooperate, to reveal.

While burdening said unruly bodies with the obligation to conform to the politicomilitaristic infrastructure of the TSA, healthism requires "the smooth integration of [the] immune system into a socio-economic world system" (Illich, 1990, p. 28). The machine body is now only as valuable as the data it produces, and the data it produces is only valuable if it is aggregated amongst a population so that it can be analyzed for patterns and trends. Human productivity has long since been recognized as valuable, but the digital tracking devices of contemporary wellness cultures "objectify and standardise the activities and capacities of heterogeneous bodies" (Till, 2014, p. 447) to enable the extraction of significance. Our body's biological processes are reified in data which, collected amongst a population, is rendered 
valuable information.

The use of wearable tech not only engages with a dynamic of alienating consumer dependency on social and economic institutions (Cowan, 1983, p. 7), but situates said user as an unpaid labourer under the guise of a kind of scrappy neoliberal entrepreneurialism (Till, 2014, p. 453). This sort of "presumption," in which users are both consumers and producers of digital media content (Till, 2014, p. 448), is consistent with the immaterial and unpaid labour implicit in social networking platforms like Facebook, whose functioning is contingent on user engagement. What's more, these platforms collect and analyze user data which in turn informs their advertising and design strategies driven by profit. The fact of our data being collected and utilized internally by platforms, or externally by third party purchasers, is not readily accessible information so that user complicity in their own subordination occurs almost exclusively unknowingly and without consent.

\section{Concluding Remarks and Proposal for Reform}

The health theatre that characterizes contemporary approaches to wellness in Western culture owes its persistent success to the generated desperation and fear of the individuals under its jurisdiction. Among the only means by which those of us under health theatre's dominion have to subvert the social order is to elucidate it. The delusion imbues patriarchal, surveilling, medical, and wellness industries with undue authority, simultaneously enlisting the individual in their own subordination. While effective immortality may be reserved for those who can afford it, this a-mortal sentiment is omnipresent in the medicalization of everyday life. It characterizes the "health" and "wellness" industries that have come to define health and wellness in North America and the West more broadly, simultaneously reviving humanism's "unshakable certainty [in] the almost boundless capacity of humans to pursue their individual and collective perfectibility" (Lacey, Caudwell, \& Beattie, 2019). Wearable tech, far from a liberatory agent, merely pathologizes the human experience, rendering users into patients whose dependency on medical authorities has been transferred to the designers, manufacturers, and distributors of the products. The dystopian nature of this vision of health inspires certain courses of action for popular resistance.

Following a call for the requisite de-privatization of healthcare and de-medicalization of everyday life, this research calls for a cultural shift to re-integrate communal forms of caring back into our conception of healthcare. Said care would be of a reproductive nature, taking place in the commons as a means of fortifying the population for structural change rather than a "regime for productivity and efficiency [and] over-determined scarcity" (Sharma, 2018, p. 
14). In the airport, the hospital, and in society broadly, citizens engaged in self-management are automatically enlisted in the surveillance of others. The pitting of individuals and communities against one another is the greatest tool for subordination as it estranges individuals from the organic tools of their environments, and creates dependencies on private interests and bureaucracy. In the medical system, individual needs and preferences are deemed irrelevant, subordinated in service of a supposed greater good. The right to withhold from preventative procedure or treatment is deemed void, lest society be burdened with the expense of curative procedure (Illich, 1975). The deleterious effect of peer-surveillance is the impossibility of collaborative or organized resistance for structural change and a fortification of the social order.

Foucault espoused death as "an anathema to a system of life: 'death is power's limit, the moment that escapes it,"' (Cisney \& Morar, 2015, p. 4). Death, therefore, is the moment at which governing bodies lose their control over the populous. The stunning finality of death in secular society is no doubt in part what inspires the culture that denies it, inspiring Ivan Illich to exclaim that "a world hostile to death" calls for "self-extinction" (Illich, 1994). The avoidance of this inevitable aspect of life bolsters the culture of fear amongst society that is exploited by those in power for literal and existential control of the citizenry.

We are made ill by incessant medical intervention, both practically and socially. The only solution to structural iatrogenesis, wherein excessive medical intervention causes societal illness (Illich, 1976, p. 27), or social iatrogenesis, wherein people whose physical presence of behaviour present outside societal standards are deemed threatening to society unless diagnosed (Illich, 1976, p. 56), is to refuse the pursuit of normate standards of being and reclaim death without permission, without shame, and "the liberty to die without diagnosis" (Illich, 1994). The individual should instead engage in communal forms of reproductive labour, those which enable the conditions for others to pursue in the necessary activities for human survival, to "eat, sleep, and rest" (Sharma, 2018, p. 14). Where health is a communal concern, death becomes a matter of fact, and can be re-introduced into the lives of the living as natural and inevitable rather than the fate of the social deviant. The contemporary practice of denying or pathologizing aging and ex-communicating the dying to specialized institutions only serves to enhance the fear of death through its systematic estrangement, and to inspire increasingly extravagant measures of life sustainment which maintain an individual's life just enough to ensure their total dependency on external authorities and institutions. The denigrated death must be re-introduced into our conception of dignity and health, so that life can be celebrated rather than relentlessly pursued. 


\section{References}

Browne, S. (2015). Dark Matters: On the surveillance of blackness. NC, USA: Duke University Press.

Cisney, V.W., \& Morar, N. (2015). Biopower: Foucault and beyond, 1-21. IL,USA: University of Chicago Press.

Crawford, R. (1980). Healthism and the medicalization of everyday life. International Journal of Health Services, 10(3), 365-388. DOI: 10.2190/3H2H-3XJN-3KAY-G9NY

Schwartz Cowan, R. (1983). More work for mother: The ironies of household technology from the open hearth to the microwave, 3-178. NY, USA: Basic Books, Inc.

Fisher, M. (2009). Capitalist realism: Is there no alternative?. Wiltshire, UK: John Hunt Publishing.

Hall, R. (2015). Terror and the female grotesque: Introducing full-body scanners to U.S. airports. Transparent traveler: The performance and culture of airport travel, 1-14. NC, USA: Duke University Press Books.

Illich, I. (1990). Health as one's own responsibility: no thank you!. Journal of Consciousness Studies, 1 (1): 25-31.

Illich, I. (1994). Brave new biocracy: Health care from womb to tomb: Life, death and the boundaries of the person. New Perspectives Quarterly, 11:1. Retrieved from: http://www. davidtinapple.com/illich/1994 biocracy.html

Illich, I. (1975). Medical nemesis: The expropriation of health, ( p. 26-114). London, Great Britain: Calder \& Boyars Ltd.

Kisner, J. (2017). The politics of conspicuous displays of self-care. The New Yorker. Retrieved from: https://www.newyorker.com/culture/culture-desk/the-politics-of-selfcare

Lacey, C., Caudwell, C., Beattie, A. (2019). The perfect user. Real Life Mag. Retrieved from: https://reallifemag.com/the-perfect-user/ 
Levenson, E. (2014). The TSA is in the business of 'security theatre', not security. The Atlantic.

Retrieved from: https://www.theatlantic.com/national/archive/2014/01/tsa-businesssecurity-theater-not-security/357599/

Ouellette, L. (2008). “Take responsibility for yourself” Judge Judy and the neoliberal citizen. In S. Murray (Ed.), L. Ouellette (Ed.), Reality TV: Remaking Television Culture. (p. 231 -250). New York University Press: New York and London.

Ropeik, D. (2011). The fear of cancer can do more harm than actual cancer. Big Think. Retrieved from: https://bigthink.com/risk-reason-and-reality/cancer-phobia-fear-of-the-diseasecan-do-as-much-harm-or-more-than-the-disease-itself

Schüll, N. D. (2016). Data for life: Wearable technology and the design of self-care. BioSocieties, $11(3), 317-333$.

Schneier, B. (2003). Beyond fear: Thinking sensibly about security in an uncertain world. Gottingen, DE: Copernicus Books.

Schneier, B. (2007, Aug. 15). Security theatre. Schneier on Security. Retrieved from: https://www. schneier.com/blog/archives/2007/08/security theate $1 . h$ tml

Sharma, S. (2017). Selfie-care and the uncommons. Blackwood, 1. Retrieved from: http:// sarahsharma.com/wp-content/uploads/2016/06/Blackwood-Issue-01-Antinomies-of-SelfCare.pdf

Sontag, S. (2001). Illness as metaphor and AIDS \& its metaphors, 3-81. London, UK: Picador.

Till, C. (2014). Exercise as labour: Quantified self and the transformation of exercise into labour. Societies, 4, 446-462. DOI: 10.3390/soc4030446

Young, L. (2018). There are thousands of health and fitness apps, and not much evidence they work: study. Global News. Retrieved from: https://globalnews.ca/news/4215969/dofitness-apps-work/ 